This item was submitted to Loughborough's Research Repository by the author.

Items in Figshare are protected by copyright, with all rights reserved, unless otherwise indicated.

\title{
An implanted antenna system for the monitoring of the healing of bone fractures
}

PLEASE CITE THE PUBLISHED VERSION

http://dx.doi.org/10.1109/LAPC.2015.7365996

PUBLISHER

(C) IEEE

VERSION

AM (Accepted Manuscript)

\section{PUBLISHER STATEMENT}

This work is made available according to the conditions of the Creative Commons Attribution-NonCommercialNoDerivatives 4.0 International (CC BY-NC-ND 4.0) licence. Full details of this licence are available at: https://creativecommons.org/licenses/by-nc-nd/4.0/

\section{LICENCE}

CC BY-NC-ND 4.0

\section{REPOSITORY RECORD}

Symeonidis, Symeon, W.G. Whittow, C.J. Panagamuwa, and Massimiliano Zecca. 2019. "An Implanted Antenna System for the Monitoring of the Healing of Bone Fractures". figshare. https://hdl.handle.net/2134/21648. 


\title{
An Implanted Antenna System for the Monitoring of the Healing of Bone Fractures
}

\author{
Symeon Symeonidis, William G. Whittow, Chinthana Panagamuwa and Massimiliano Zecca \\ School of Electronic, Electrical and Systems Engineering, Loughborough University, Loughborough, Leicestershire, UK \\ S.Symeonidis@lboro.ac.uk,w.g.whittow@lboro.ac.uk, c.j.panagamuwa@lboro.ac.uk,m.zecca@lboro.ac.uk
}

\begin{abstract}
An implanted antenna system consisting of two monopoles attached on a metal plate for the monitoring of the healing of bone fractures has been investigated. The proposed structure has been simulated on a three layer body phantom model and the $S_{21}$ response of the system is evaluated as the bone fracture that is introduced in the phantom gradually heals turning from blood to bone marrow and bone cortical in five discrete steps.
\end{abstract}

Keywords- wireless communications, implanted antennas, bone phantoms, fracture monitoring

\section{INTRODUCTION}

Designing antennas that are implanted inside the human body is a challenging task for engineers but with great benefits in the field of medicine. Such devices can add up and possibly improve doctors' tools for diagnosis of patients' conditions in terms of timing and quality of evaluation. The human body is a lossy medium, therefore antennas operating at lower frequencies are more effective in terms of the skin depth penetration. This leads to bigger antenna geometries, posing a great challenge in designing them due to the limited space inside the human body. Over the last ten years, multiple authors have addressed these challenges in literature, and have proposed a variety of optimized geometries of implanted antennas for different applications. A good trade-off between frequency of operation, antenna efficiency and size was found to be based on the Medical Devise Radiocommunications Service (MedRadio) frequency band in the $401-406 \mathrm{MHz}$ range [1]-[3] and the Industrial, Scientific and Medical (ISM) radio bands in the 2.44 to $2.46 \mathrm{GHz}$ range [4]-[6]. Most of the proposed applications in the literature include incorporation of the antenna under the skin, fat or muscle tissues [7]-[9]. Others include implants beneath the skull for monitoring of brainwave signals [10], intraocular implementation of antennas for retinal prosthesis [11], ingestible capsule antennas for the monitoring of human intestines [12] and antennas operating in the GPS frequency range for the localization of people suffering from Alzheimer's disease [13].

The purpose of this work is to propose an implanted antenna system able to monitor the rate of healing of bone fractures. Robust healing of fractures in bones is a complicated biological process requiring continuous monitoring evaluation and mechanical assistance for the restoration of the bone to its original state [14]. Healing in bones requires 4 to 40 weeks depending on the number of fractures, the age and the type of the bone. According to literature there is no standard defining when a fracture is healed, therefore the evaluation of a healing fracture is based on predetermined time points [15]. The development of an implanted antenna monitoring system could provide orthopedics with a continuous indicator of the bone's condition. This could be crucial for the healing process in order to determine if further treatment is required and also greatly reduce the number of $\mathrm{x}$-rays required for a proper evaluation of the bone's condition.

\section{The ANTENNA System ARChitecture AND THE THREE LAYER BONE PHANTOM}

The proposed antenna system is attached to the metal plate that is implanted by the surgeon on the fractured bone. The purpose of the metal plate is to provide mechanical function for the stabilization and positioning that is crucial for the healing process of the broken bone. The antenna system consists of two monopoles, $3 \mathrm{~cm}$ length and $1 \mathrm{~mm}$ radius each (Fig.1). The monopoles are considered to be screwed in the bone ensuring the stability of the metal plate that also operates as a ground plane. The dimensions of $7 \times 2 \mathrm{~cm}$ were chosen for the metal plate and $\mathrm{D}$ is the distance between the two monopoles.

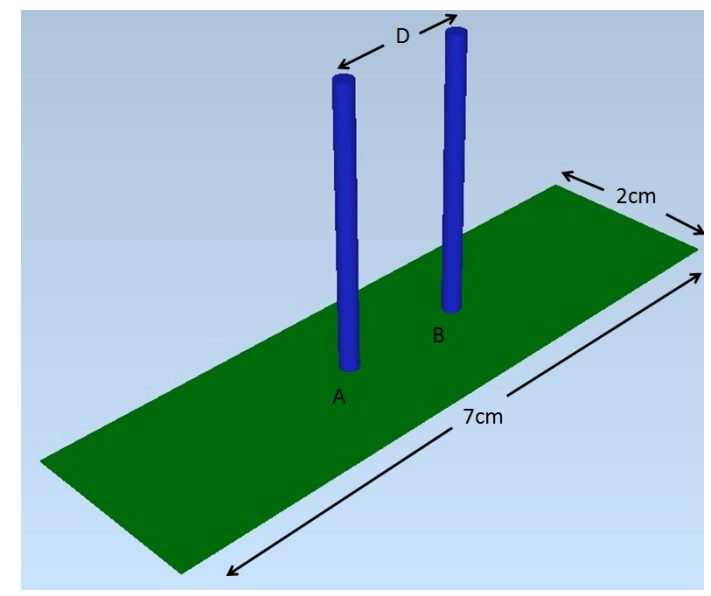

Figure 1: The proposed antenna system 
Table 1: The dielectric properties used for the three layered bone phantom

\begin{tabular}{|c|c|c|}
\hline & $\begin{array}{c}\text { Relative } \\
\text { Permittivity } \\
\varepsilon_{r}\end{array}$ & $\begin{array}{c}\text { Conductivity } \\
\sigma,(\mathrm{S} / \mathrm{m})\end{array}$ \\
\hline Muscle & 53.29 & 1.45 \\
\hline Bone Marrow & 5.34 & 0.07 \\
\hline Bone Cortical & 11.65 & 0.31 \\
\hline Blood & 59 & 2.18 \\
\hline
\end{tabular}

A bone phantom consisting of three layers: marrow, cortical and muscle (Fig. 2) was used. Each of the cylinders had $15 \mathrm{~cm}$ length, the outer cylinder had $10 \mathrm{~cm}$ radius, the middle $1.5 \mathrm{~cm}$ and the inner $1 \mathrm{~cm}$. The dielectric properties of muscle tissue, bone cortical and bone marrow at $2 \mathrm{GHz}$ were appointed to the cylinders, as shown in Table 1. In the middle of the simulated phantom, a fracture was introduced, consisting of two concentric cylinders with $2 \mathrm{~mm}$ thickness each. The first had the radius of the bone marrow cylinder $(1 \mathrm{~cm})$ and the second, the radius of bone cortical $(1.5 \mathrm{~cm})$. Five different states were considered, emulating the condition of the fracture as it heals, turning from blood to bone. At the initial state, the dielectric properties of blood were given to the fracture, changing by a $25 \%$ step towards the properties of marrow and cortical until the bone reached a completely healed state. At the fifth step the bone is considered $100 \%$ healed and the fracture no longer exists inside the phantom. The two monopoles of the proposed antenna system, were placed on each side of the fracture (Fig. 3) and three different distances, D, $1.5 \mathrm{~cm}, 5 \mathrm{~cm}$ and $9 \mathrm{~cm}$ between them were tested in order to investigate the optimal propagation from monopole A to monopole B.

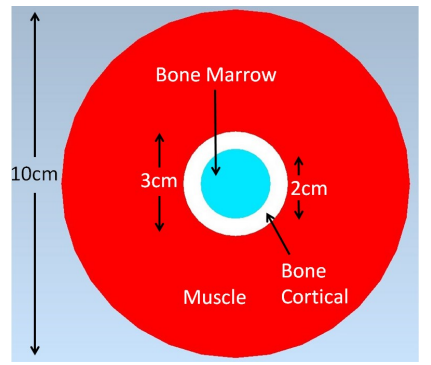

(a)

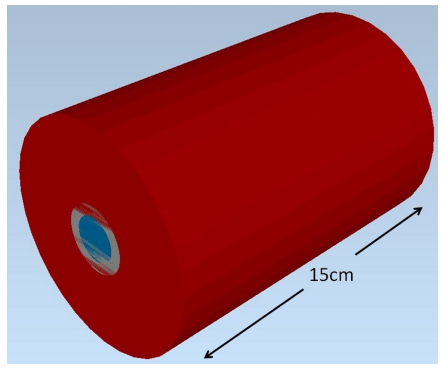

(b)
Figure 2: The three layer bone phantom: (a) front view, (b) side view
Table 2: The dielectric properties of the fracture during the healing progress

\begin{tabular}{|c|c|c|c|c|}
\hline & \multicolumn{2}{|c|}{ Bone Marrow cylinder } & \multicolumn{2}{c|}{ Bone Cortical cylinder } \\
\hline $\begin{array}{c}\text { Bone } \\
\text { Damage }\end{array}$ & $\begin{array}{c}\text { Relative } \\
\text { Permittivity } \\
\varepsilon_{r}\end{array}$ & $\begin{array}{c}\text { Cond. } \\
\sigma,(\mathrm{S} / \mathrm{m})\end{array}$ & $\begin{array}{c}\text { Relative } \\
\text { Permittivity } \\
\varepsilon_{r}\end{array}$ & $\begin{array}{c}\text { Cond. } \\
\sigma,(\mathrm{S} / \mathrm{m})\end{array}$ \\
\hline $100 \%$ & 59 & 2.18 & 59 & 2.18 \\
\hline $75 \%$ & 45.57 & 1.64 & 47.05 & 1.7 \\
\hline $50 \%$ & 32.16 & 1.12 & 35.25 & 1.24 \\
\hline $25 \%$ & 18.75 & 0.59 & 23.45 & 0.08 \\
\hline $0 \%$ & 5.34 & 0.07 & 11.65 & 0.31 \\
\hline
\end{tabular}

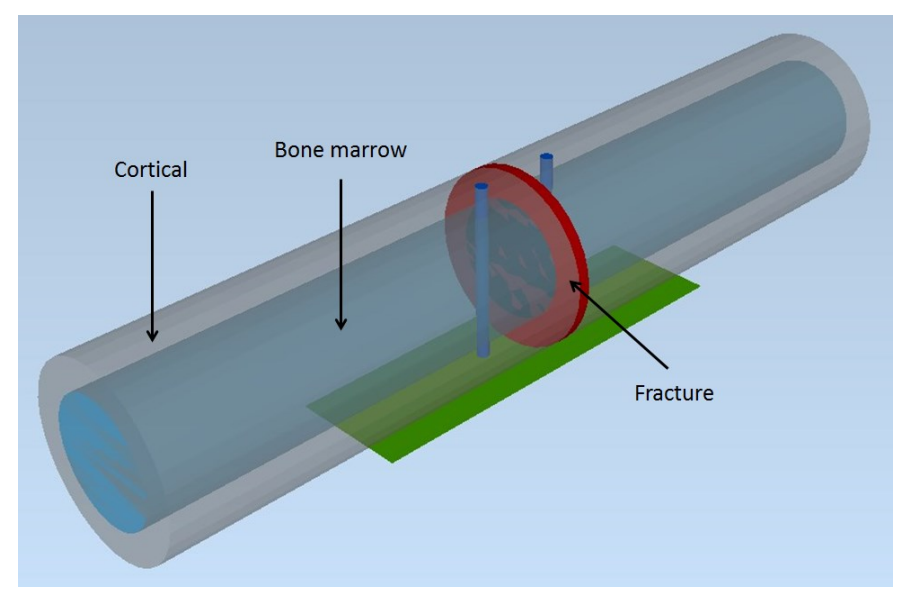

Figure 3: The position of the fracture with the muscle layer hidden

\section{SIMULATION RESULTS OF THE PROPOSED STRUCTURE}

For the simulation of the proposed structure, the EMPIRE XPU EM solver was used. The fracture was placed at the center of the phantom and the properties of blood tissue were assigned to it. Table 2 describes the change of the dielectric properties of the introduced fracture in five steps. The results of the simulation (Fig. 4) show that the $S_{21}$ response of antenna system is greatly affected as the length between the monopoles increased. The distances of $5 \mathrm{~cm}$ and $9 \mathrm{~cm}$ were considered to be inadequate for proper measurement of the $S_{21}$ due to the low $\mathrm{dB}$ values $\left(S_{21}<-60 \mathrm{~dB}\right)$, therefore the optimal distance selected for the rest of the simulations was $1.4 \mathrm{~cm}$. 


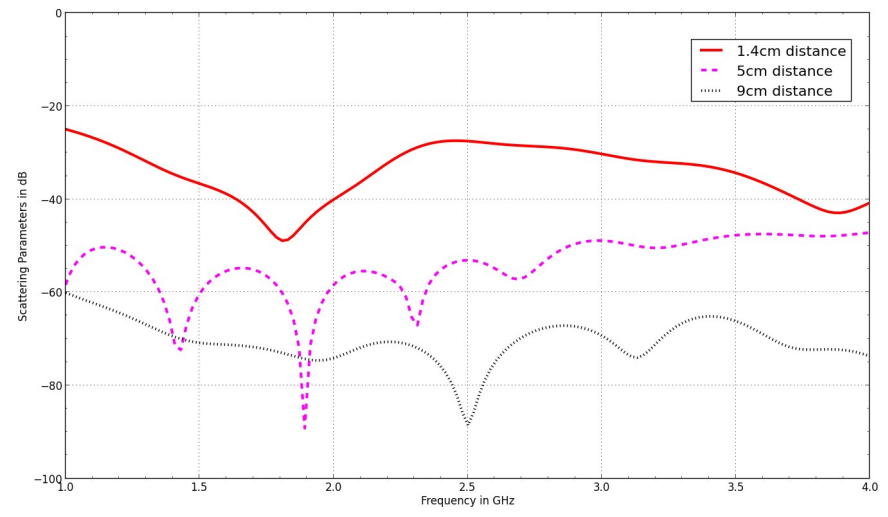

Figure 4: The $S_{21}$ response of the antenna system for three different distances between monopoles

According to the results shown in Figure 5, as the fracture changes from blood to bone, the $S_{21}$ magnitude at $1.8 \mathrm{GHz}$ improves by $2.1 \mathrm{~dB}$ from Step 1 to Step 2 and more than $3 \mathrm{~dB}$ for each the next steps, see Table 3 . This trend shows that it is possible to monitor changes in the state of a fractured bone as it heals. The simulation results of the electric fields (Fig. 6) show that the near field of the monopoles are larger in magnitude and have a different distribution when the dielectric properties of the fracture are closer to the dielectric properties of blood.

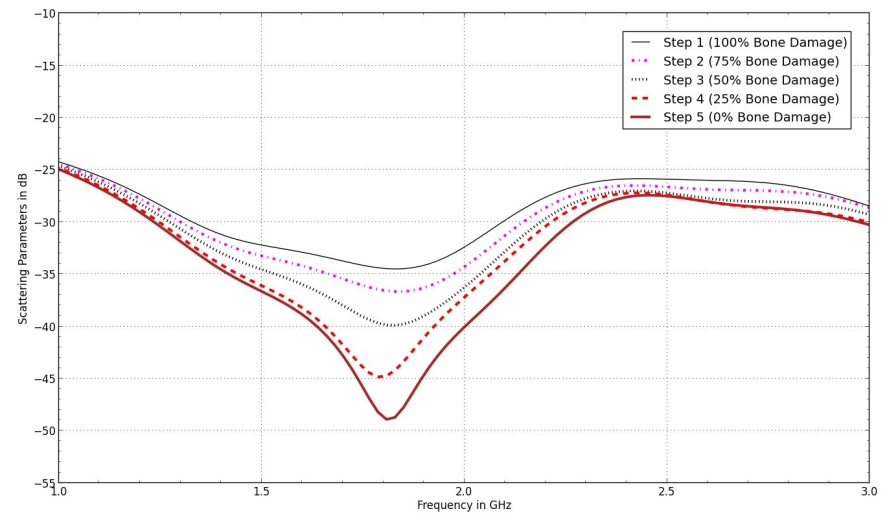

Figure 5: The $S_{21}$ response of the monopoles separated by $1.4 \mathrm{~cm}$. The dielectric properties of the fracture change from blood to bone in five steps

Table 3: The $S_{21}$ response at $1.8 \mathrm{GHz}$ for each step of the bone fracture

\begin{tabular}{|l|c|}
\hline & $S_{21}$ \\
\hline Step 1 (100\% Bone Damage) & -34.43 \\
\hline Step $2(75 \%$ Bone Damage $)$ & -36.54 \\
\hline Step $3(50 \%$ Bone Damage $)$ & -39.80 \\
\hline Step 4 (25\% Bone Damage $)$ & -44.79 \\
\hline Step 5 (0\% Bone Damage $)$ & -48.65 \\
\hline
\end{tabular}
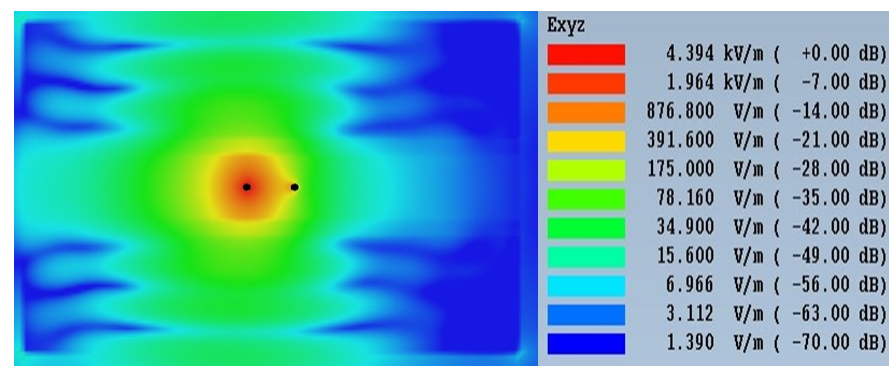

(a)
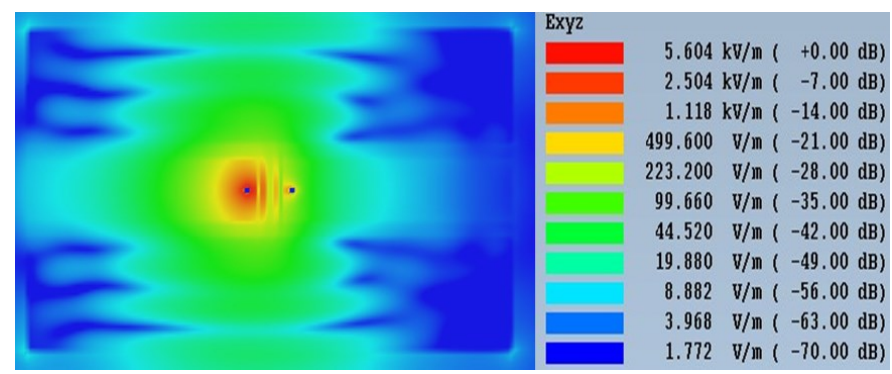

(b)
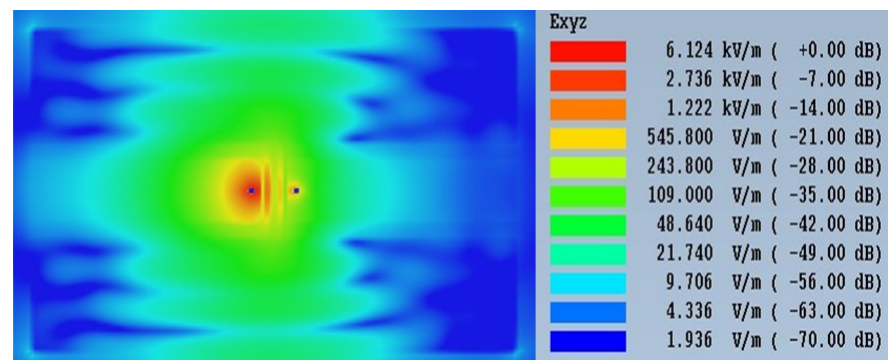

(c)

Figure 6: The electric field distribution at $1.8 \mathrm{GHz}$ for: a) $0 \%$ damage, b) $50 \%$ damage, c) $100 \%$ damage

\section{CONCLUSION}

An implanted antenna system consisting of two monopoles vertically attached to a metal plate for bone fracture monitoring applications has been proposed. The $S_{21}$ magnitude for the selected distance has been shown to improve as the fracture between the monopoles healed gradually by turning from blood to bone marrow and bone cortical. Future work includes an investigation of the near field phenomena of the two monopoles in the human body and the $S_{21}$ response for different geometries. The work will then be extended in an anatomical phantom model.

\section{REFERENCES}

J. Kim and Y. Rahmat-Samii, "Implanted antennas inside a human body: Simulations, designs, and characterizations," IEEE Trans. Microw. Theory Tech., vol. 52, no. 8, pp. 1934-1943, 2004. 
[2] P. Soontornpipit, C. M. Furse, and Y. C. Chung, "Design of implantable microstrip antenna for communication with medical implants," IEEE Trans. Microw. Theory Tech., vol. 52, no. 8, pp. 1944-1951, 2004.

[3] T. Karacolak, A. Z. Hood, and E. Topsakal, "Design of a dual-ban implantable antenna and development of skin mimicking gels for continuous glucose monitoring," IEEE Trans. Microw. Theory Tech., vol. 56, no. 4, pp. 1001-1008, 2008.

[4] W. Xia, K. Saito, M. Takahashi, and K. Ito, "Performances of an implanted cavity slot antenna embedded in the human arm," IEEE Trans. Antennas Propag., vol. 57, no. 4, pp. 894-899, 2009.

[5] R. Warty, M. R. Tofighi, U. Kawoos, and A. Rosen, "Characterization of implantable antennas for intracranial pressure monitoring: Reflection by and transmission through a scalp phantom," IEEE Trans. Microw. Theory Tech., vol. 56, no. 10, pp. 2366-2376, 2008

[6] S. Soora, K. Gosalia, M. S. Humayun, and G. Lazzi, "A comparison of two and three dimensional dipole antennas for an implantable retinal prosthesis," IEEE Trans. Antennas Propag., vol. 56, no. 3, pp. 622-629, 2008.

[7] T. Karacolak, R. Cooper, and E. Topsakal, "Electrical properties of rat skin and design of implantable antennas for medical wireless telemetry," IEEE Trans. Antennas Propag., vol. 57, no. 9, pp. 2806 $2812,2009$.

[8] J. Abadia, F. Merli, J. F. Zurcher, J. R. Mosig, and A. K. Skrivervik, "3D-Spiral small antenna design and realization for biomedical telemetry in the MICS band," Radioengineering, vol. 18, no. 4, pp. 359-367, 2009.
[9] E. Y. Chow, C. L. Yang, A. Chlebowski, S. Moon, W. J. Chappell, and P. P. Irazoqui, "Implantable wireless telemetry boards for in Vivo transocular transmission," IEEE Trans. Microw. Theory Tech., vol. 56 , no. 12 , pp. $3200-3208,2008$.

[10] Z. N. Chen, G. C. Liu, and T. S. P. See, "Transmission of RF signals between MICS loop antennas in free space and implanted in the human head," IEEE Trans. Antennas Propag., vol. 57, no. 6, pp. $1850-1854,2009$.

[11] K. Gosalia, M. S. Humayun, and G. Lazzi, "Impedance matching and implementation of planar space-filling dipoles as intraocular implanted antennas in a retinal prosthesis," IEEE Trans. Antennas Propag., vol. 53, no. 8, pp. 2365-2373, 2005.

[12] P. M. Izdebski, H. Rajagopalan, and Y. Rahmat-Samii, "Conformal ingestible capsule antenna: A novel chandelier meandered design," IEEE Trans. Antennas Propag., vol. 57, no. 4, pp. 900-909, 2009.

[13] M. Z. Azad and M. Ali, "A miniature implanted inverted-F antenna for GPS application,” IEEE Trans. Antennas Propag., vol. 57, pp. $1854-1858,2009$

[14] K. D. Hankenson, G. Zimmerman, and R. Marcucio, "Biological perspectives of delayed fracture healing," Injury, vol. 45, pp. S8S15, 2014.

[15] P. Augat, M. Faschingbauer, K. Seide, K. Tobita, S. a. Callary, L. B Solomon, and J. H. Holstein, "Biomechanical methods for the assessment of fracture repair," Injury, vol. 45, pp. S32-S38, 2014. 